Int. J. Morphol.,

35(2):711-718, 2017

\title{
Descripción de las Láminas Anatómicas de la Universidad de Chile, un Monumento Nacional
}

\author{
Description of the Anatomical Plates of the Universidad de Chile, a National Monument
}

Julio L. Cárdenas Valenzuela ${ }^{1}$; Michele Dinator Esterioº \& Jorge Madariaga Lagunas ${ }^{3}$

CÁRDENAS, V. L. J.; DINATOR, E. M. \& MADARIAGA, L. J. Descripción de las láminas anatómicas de la Universidad de Chile, un monumento nacional. Int. J. Morphol., 35(2):711-718, 2017.

RESUMEN: Bajo el Anfiteatro de Anatomía del Instituto de Anatomía de la Universidad de Chile, construido en 1921, se encontraron en el año 2003, 475 láminas anatómicas además de 5 litografías utilizadas para la docencia de la disciplina en el siglo XIX. Muchas generaciones, incluso de docentes de Anatomía Normal que pasaron por las aulas desconocieron tanto su existencia como la importancia cultural que tenían. Con el objeto de remediar esta situación y de preservarlas es que se inicia ese año un registro digital de todas estas obras como una forma de darle valor y la importancia que dicho material tiene y lograr su protección futura. Dispuestas por áreas temáticas, las láminas fueron realizadas por alumnos, docentes y personas externas como una herramienta más que permitiera la enseñanza de la Anatomía en un tiempo dónde las diapositivas y otros medios audiovisuales digitales no existían aún. Utilizando distintas técnicas; lienzos enrollados y guardados en muebles dispuestos especialmente para ello; conservados por el frío y la obscuridad, quedaron ajenos a su destrucción. Por ello, para evitar su deterioro y permitir su conservación, es que se procedió a digitalizar estas obras para luego permitir la creación de un catálogo de las mismas con el fin de preservarlas para las generaciones futuras. Este trabajo cobra nuevo impulso toda vez que el año 2016, el Estado de Chile nomina a estas láminas anatómicas como Monumento Nacional, por su carácter histórico.

PALABRAS CLAVE: Láminas anatómicas; Enseñanza Anatomía; Monumento nacional.

\section{INTRODUCCIÓN}

Desde tiempos pretéritos, en la antigua Grecia y Roma, la Anatomía se enseñaba en forma práctica utilizando la visión directa de los cadáveres a través de disecciones tanto en humanos como en animales, lo que se prolongaría hasta periodos de la Edad Media y Renacimiento. Esta sería una forma de conocer el cuerpo humano muy básica no ajena a nuestra población aborigen americana.

Sin embargo, con posterioridad, el conocimiento teórico de la Anatomía que inicialmente se expresaba en comunicaciones de trasmisión oral, y luego a través de exhibición de láminas de libros en forma directa después, llegaría a la difusión de imágenes en el aula por medios más masivos con el fin de llegar a más observadores. Aparece el uso de la pizarra y tiza para realizar dibujos más grandes (Guzmán Cortés, 1964) pero su defecto era la transitoriedad de la imagen, además de ser inicialmente monocromática. De esta forma surge la necesidad de plasmar a través de dibujos en tela u otro soporte, las imágenes anatómicas para así exhibirlas a una mayor audiencia al poder reproducirlas no sólo de mayor tamaño que el natural, sino también en colores más cercano a la realidad.

Sólo posteriormente veríamos aparecer junto con los avances tecnológicos, al proyector opaco o epidiascopio, retroproyector, diapositivas y data-show que nos acompaña hasta el día de hoy.

Bajo los asientos del anfiteatro de Anatomía de la Universidad de Chile, construido en el año 1921 se descubren 480 láminas de representación anatómica, realizadas entre los años 1903 a 1956, las que dispuestas en rollos, permanecieron por más de 100 años como mudos testigos de una forma de enseñanza no exclusivas de nuestro Instituto. En efecto, láminas similares se encontrarían por el autor en otras Escuelas de Medicina surgidas posteriormente como la Escuela de

\footnotetext{
${ }^{1}$ Médico Cirujano, internista, Prof. Asistente ICBM, Anatomia y Biología del Desarrollo, Facultad de Medicina, Universidad de Chile, Chile.

${ }^{2}$ Diseñadora Gráfica, Universidad de Chile, Chile.

${ }^{3}$ Médico Cirujano, Universidad de Chile, Chile.
} 
Medicina de la Universidad de Concepción en 1924 y la Escuela de Medicina de la Pontificia Católica de Chile, en 1950.

Estas láminas fueron utilizadas en forma regular por los catedráticos y estudiantes en el contexto de enseñanza de la anatomía en la Escuela de Medicina (Laval, 1964) durante la primera mitad del siglo XX.

Se evidenció el abandono, falta de protección y cuidado en que estaban estas láminas, lo que se notaba no sólo por el estado de las mismas, sino también por su falta de limpieza, y pérdida de algunas de ellas incluso, almacenadas erróneamente.

\section{MATERIAL Y METODO}

Se procedió a efectuar un catastro e identificación del material visual dispuesto en rollos guardados bajo el Anfiteatro de Anatomía. (Fig. 1)

Estaban ubicados en un mueble semicircular de madera color café moro estilo Cruz-Montt que dispone de alrededor de 667 casilleros siguiendo la curvatura del Anfiteatro. Según área temática, este mueble está dividido en 4 zonas designadas por una letra mayúscula desde la $\mathrm{A}$ a la $\mathrm{D}$, de derecha a izquierda. En cada una de ellas, los cuadros se encuentraban enrollados en sí mismos, en casilleros construidos con este fin en cada una de las zonas, asignándosele una identificación consistente en una letra minúscula desde la "a" a la "m" según el tema tratado. A continuación un número en particular en el casillero coincide con la identificación que cada uno de estos cuadros presenta en un círculo de cartón unido a un cordel en un extremo del listón superior pintado de color negro.

Inicialmente es necesario ordenar y asignar correctamente cada lámina con su respectivo casillero por cuanto las láminas no siempre coincidían con los casilleros asignados, lo que es posible realizar ya que en vitrinas dispuestas al lado de cada una de las divisiones del mueble existían unas listas detalladas de los cuadros ordenados por área temática. (Fig. 2)

Se procedió inicialmente a desenrollar estas láminas y limpiarlas, para luego reparar algunas dañadas y se efectuó luego la captura digital fotográfica de cada una de ellas.

Se retiraron cuidadosamente las láminas en grupos de no más de 6-8 por vez, para no dañarlos en su acopio. Se procedió a la medición de cada una de las láminas y se registraron los resultados en una planilla Excel.

Cada lámina se expuso al menor tiempo necesario para la captura de la imagen evitando su exposición directa a la luz solar. En algunos casos, fue necesaria más de una toma según el interés docente y detalles de la muestra. Para ello se utilizó en el año 2006 una cámara digital marca Sony de 4.1 Megapixeles Cyber shoot, DSC-S85 de resolución 1600.

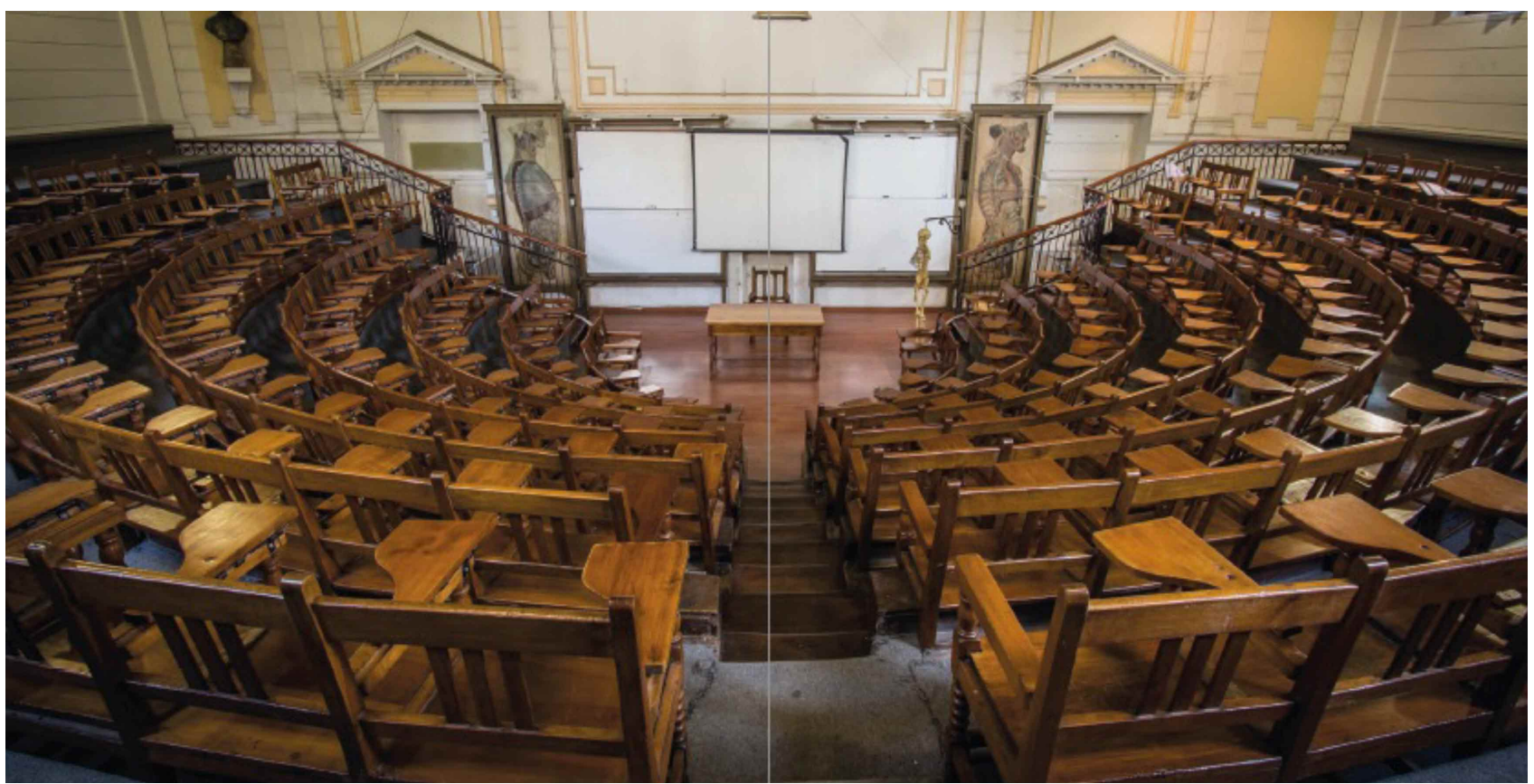

Fig. 1. Anfiteatro de Anatomía, Instituto de Anatomía Humana, Facultad de Medicina, Universidad de Chile. Fotografía de Marco Saavedra, año 2016. 


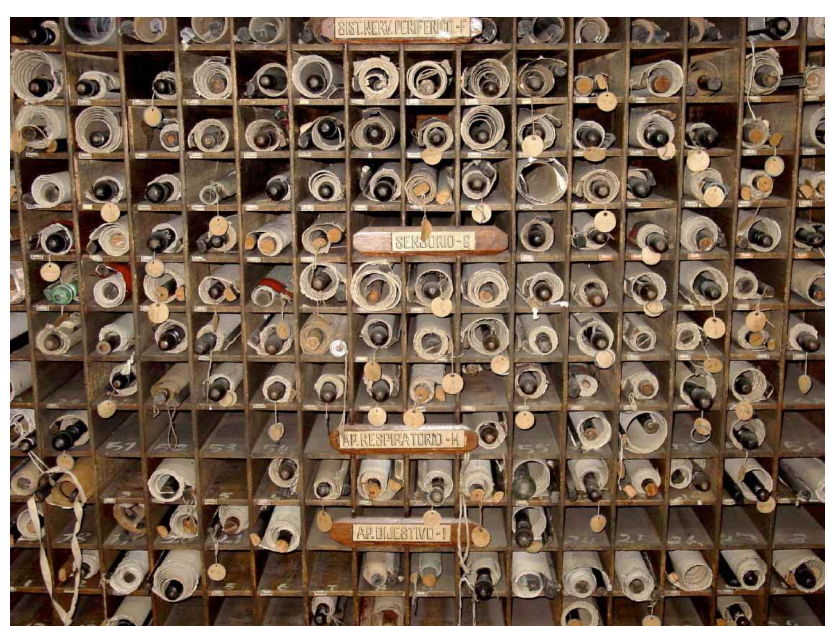

Fig. 2. Casilleros láminas anatómicas. Fotografiado por Julio Cárdenas en 2003.

Se analizaron y procesaron las imágenes en computador utilizando un programa Pixela y Paint Shop Pro 8 guardando las imágenes en formato JPG para su análisis posterior. Luego las imágenes se procesaron visualmente y encuadraron. (Fig.3).

\section{RESULTADOS}

Se analizaron láminas, autores y referentes o fuentes de origen.

De las láminas: De los 667 casilleros disponibles, sólo 480 tenían láminas en su interior; uno de ellos con 2 láminas al parecer por ser del mismo tema. Cinco con litografías compradas en Estados Unidos de Norteamérica. Las láminas tenían un largo relativamente constante, aproximadamente de $100 \times 20 \mathrm{~cm}$ en promedio, variando entre $\operatorname{los} 60 \mathrm{~cm}$ a 174 $\mathrm{cm}$. En relación a su ancho era menos variable y fluctuaba entre $65 \mathrm{~cm}$ y $106 \mathrm{~cm}$ con un promedio de $95 \mathrm{~cm}$.

Las láminas disponían de un cordel para colgarlas, cordel que se anudaba en listones negros de madera dispuestos en todo su ancho, superior e inferior torneados en sus extremos, en el cual colgaba un círculo de cartón que tenía la letra y el número asignados. El soporte era de tela y cartulina encolada los otros.

Las láminas anatómicas de distribuían en 13 áreas temáticas según se muestra Tabla I.

De ellos se desprende que la sección (D) Angiología

Tabla I. Listado de mayor a menor número de las 475 láminas anatómicas por sección. La letra mayúscula señala el orden que cada tema tiene en el mueble. 475 Láminas chilenas; 5 Litografías; 480 Total

\begin{tabular}{ll}
\hline (D) & Angiología con 81 láminas \\
(A) & Osteología con 72 láminas \\
(C) & Miología con 71 láminas \\
(F) & Neurología con 55 láminas \\
(E) & Sistema Nervioso Central con 44 láminas \\
(G) & Órganos de los Sentidos con 33 láminas \\
(I) & Digestivo con 26 láminas \\
(B) & Artrología con 25 láminas \\
(J) & Urogenital con 24 láminas \\
(H) & Respiratorio con 18 láminas \\
(M) & Topografía con 11 láminas \\
(K) & Topografía del Abdomen con 10 láminas \\
(L) & Endocrino con 5 láminas \\
\hline
\end{tabular}

es la que posee mayor número de láminas con un total de 81 y que la sección (L) Endocrino es la que posee menor número de láminas con un total de 5. (Fig. 4)

Existen diversas técnicas utilizadas por los autores, entre las que se identifica: tinta china, acuarela, témpera, óleo, lápiz grafito, etc.

De un total de 480 láminas, 300 (62,5 \%) están fechadas y en $180(37,5 \%)$ se desconoce su fecha de creación.

De un total de 475 láminas de autoría nacional, 299
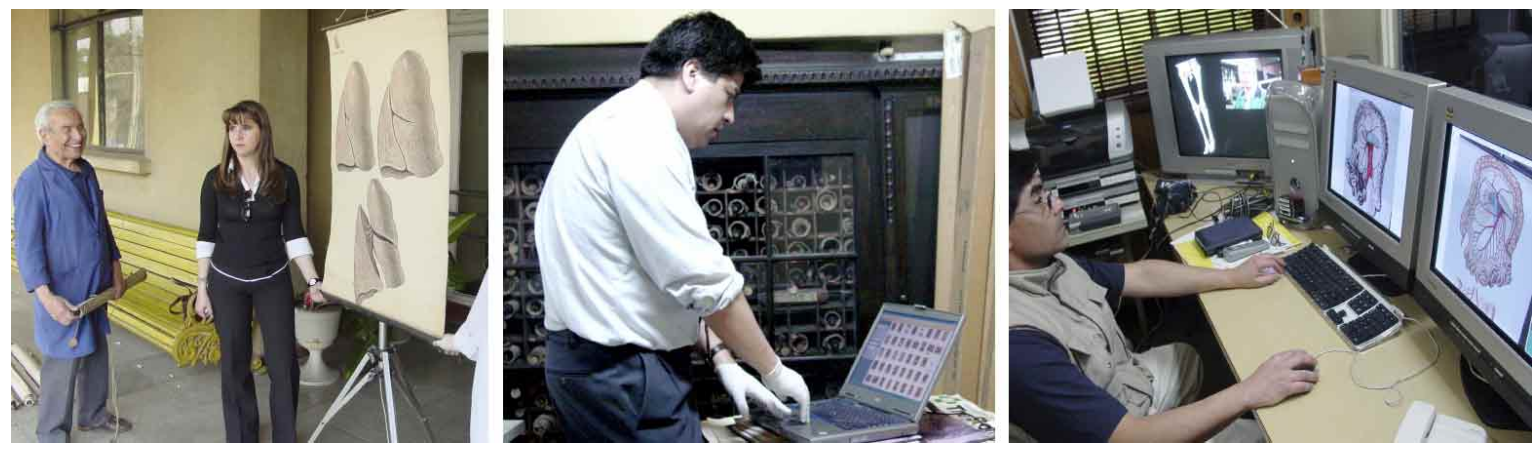

Fig. 3. Diversas etapas del procesamiento de las imágenes digitales obtenidas de las láminas anatómicas del Instituto de Anatomía de la Universidad de Chile. 


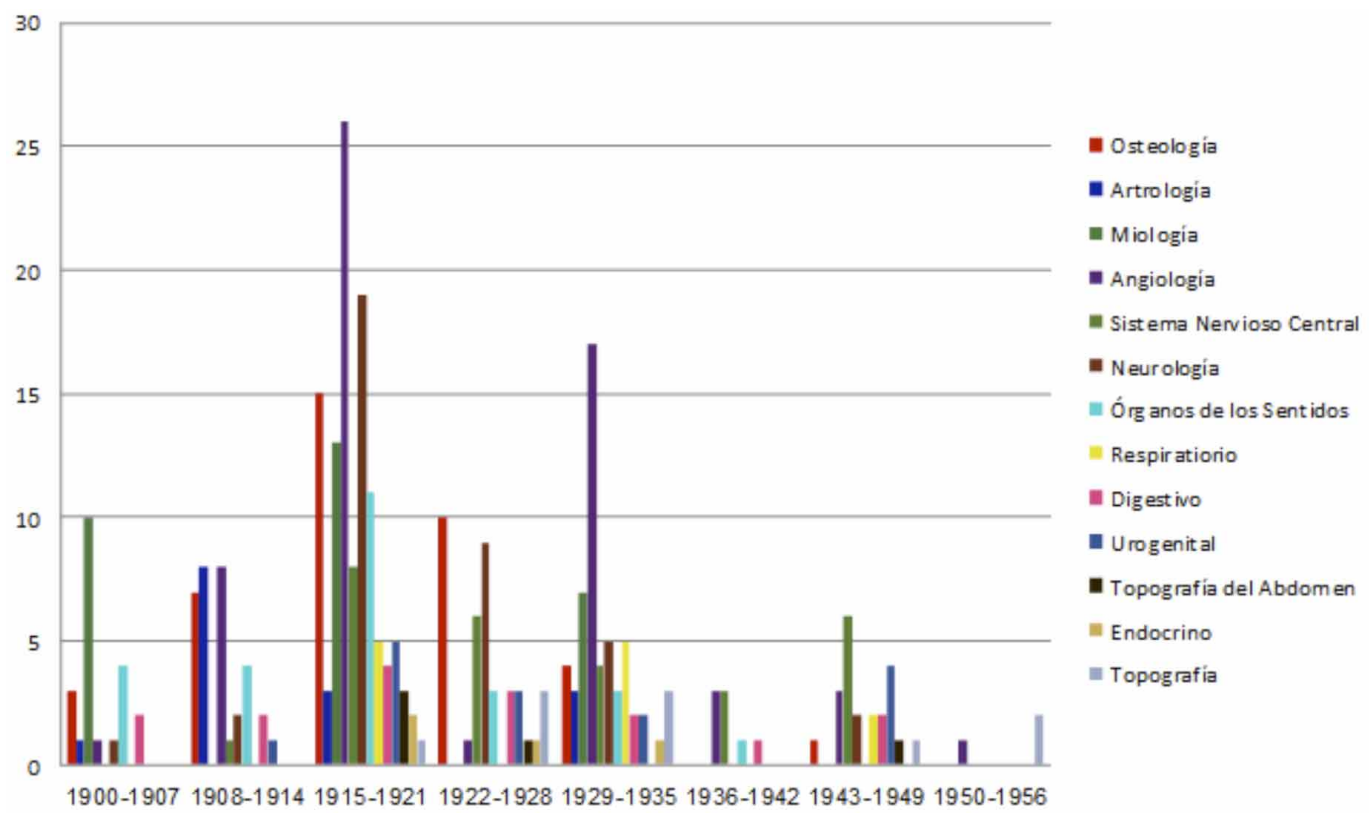

Fig. 4. Número de láminas anatómicas por tema v/s año de elaboración del Instituto de Anatomía de la Universidad de Chile.

$(62,9 \%)$ están fechadas y de $176(37,1 \%)$ se desconoce la fecha de creación. El intervalo de tiempo en que existe mayor productividad de láminas es entre los años 1915 y 1921 con 118 láminas. La menor producción se produce en el intervalo final entre los años 1950 y 1956 con 4 láminas. (Fig. 5)

En relación a las técnicas utilizadas en su elaboración, es un trabajo que se realizará a futuro al programar su restauración.

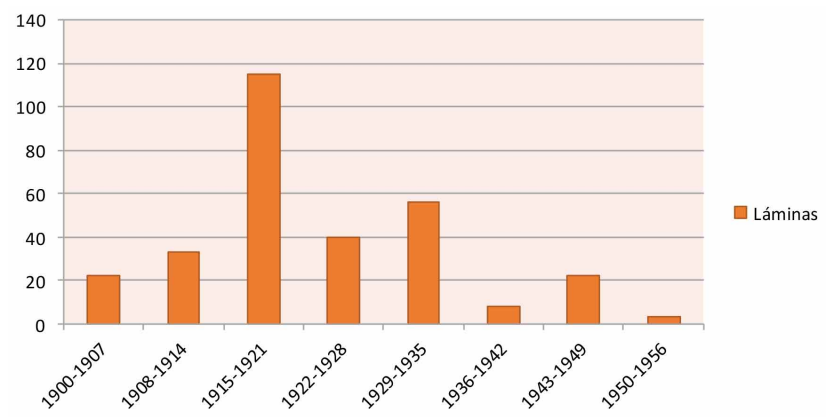

Fig. 5. Número de láminas anatómicas v/s intervalo de tiempo, del Instituto de Anatomía de la Universidad de Chile.

De los autores: De 475 láminas, 361 (76\%) poseen firma y $114(24 \%)$ no tienen firma o la inscripción es ilegible impidiendo la atribución de un nombre como autoría. Los autores identificados por su firma legible ascienden a 58, destacando 10 de ellos por su producción con 194 obras. En efecto, concentran el $40 \%$ del total de cuadros. (Tabla II)
Tabla II. Listado de 10 autores con mayor número de láminas anatómicas producidas que se encuentran en el Instituto de Anatomía de la Facultad de Medicina de la Universidad de Chile.

\begin{tabular}{lc}
\hline Autor & Láminas \\
\hline J. Cecchi & 42 \\
Juan Frutos M & 33 \\
A. Brieva D & 24 \\
E. Waugh Rojas & 18 \\
Gustavo Latorre Troncoso & 17 \\
F. Contador C. & 14 \\
Ricardo Zuñiga Latorre & 13 \\
A. Prado Reyes & 12 \\
Zúñiga & 11 \\
A. Pérez F. & 10 \\
\hline
\end{tabular}

Las 2 láminas más antiguas están fechadas el año 1903 y pertenecen a Luis Vargas Salcedo y J. C. Villegas y la más nueva a Gazaui fechada en el año 1956.

De los autores, se infiere que las láminas fueron realizadas principalmente por alumnos, pero también profesores y algunos artistas externos. Algunos estudiantes se dedicaron posteriormente al arte, como es el caso de Juan Frutos Martrat quién estudió Medicina hasta tercer año, se retiró y siguió su afición artística ganando premios en Europa, quien además fue el autor de los dos megacuadros que decoran el frontis del Anfiteatro, y que también es posible apreciar en esta obra (entrevista nietas de Frutos M. 2006). De aproximadamente 1 metro de ancho y 3 de alto, decoran el frontis 
del Anfiteatro, mostrando ambos un corte sagital de un cadáver de sexo masculino, los que aún son posible de apreciar. Estas obras, así como otras, se dibujarían de grabados presentes en el libro Atlas of Human Anatomy and Surgery (1831-1854) de J.M. Bourgery.

Además de docentes y estudiantes de la Facultad de Medicina, se identificaron artistas que participaron en la creación de las láminas como Pedro Luna Pérez, autor de tres láminas entre 1916 y 1918. Contratado para ello y Premio Nacional de Arte elegido posteriormente, pertenece a una cofradía denominada Los Caimanes, en la que se reúnen estudiantes, artistas y pintores. Él, junto a Pedro Lira y Camilo Mori, pertenecerían al grupo de la "Generación del trece" o "Heróica Capitania" denominación dada por Pablo Neruda a este grupo de artistas por presentar sus obras en conjunto ese año en una exposición en el Bellas Artes. (Zamorano, 2008).

Otros, como Jenaro Cecchi A, se recibiría en 1922, en la promoción junto a Sótero del Río y Alfredo Yazigi (Figs. 4 y 5).

\section{De los referentes;}

De un total de 475 láminas de autoría nacional se ha comprobado que 341 láminas $(71,79 \%)$ corresponden a obras derivadas de ilustraciones presentes en tratados anatómicos. De ellas, 288 láminas $(84,46 \%$ ) corresponden a obras derivadas de las ilustraciones presentes en tratados de Leo Testut (Dinator Esterio, 2014) (Tabla III) (Fig. 6).

\section{Autores y textos de referentes originales:}

Testut, Leo. Tratado de Anatomía Humana (Traité d'anatomie humaine) (1887) y Traité d'anatomie topograp que avec applications medico-chirurgicales. L Testut y $\mathrm{O}$.

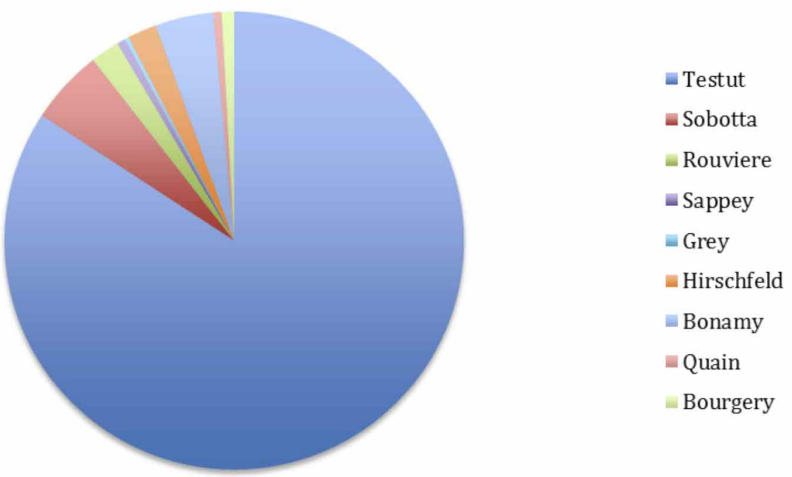

Fig. 6. Frecuencia relativa de autores y textos referentes originales de las láminas anatómicas del Instituto de Anatomía, de la Facultad de Medicina d la Universidad de Chile.

Jacob (1922) (Fig.7).

Sobotta, Johannes. Atlas de anatomía descriptiva humana (Atlas der descriptiven Anatomie des Menschen in 3 Banden) (1904-1907).

Rouvière, Henri. Anatomía Humana, Descriptiva y Topográfica (1933).

Sappey, Philibert-Constant. Traité d'anatomie descriptive (1847-1863).

Gray, Henry. Anatomía: Descriptiva y quirúrgica (Anatomy: Descriptive and Surgical) (1858).

Hirschfeld, Ludovic. Névrologie ou description et iconographie du système nerveux et des organes des sens de l'homme (1853).

Bonamy, C. y Broca, P. Atlas d'anatomie descriptive du corps humain, (1866).

Jones Quain. Quain's Elements of Anatomy (1828).

Bourgery, Jean M. Traité complet de l'anatomie de l'homme (1831-1854).

Tabla III. Distribución de total de láminas anatómicas por temas y porcentaje de Obras derivadas.

\begin{tabular}{lccc}
\hline Sección & Total de Obras & Obras Derivadas & $\%$ Obras Derivadas \\
\hline Osteología & 72 & 61 & $84,73 \%$ \\
Artrología & 25 & 19 & $76 \%$ \\
Miología & 71 & 46 & $64,79 \%$ \\
Angiología & 81 & 49 & $60,49 \%$ \\
Sistema Nervioso Central & 44 & 28 & $63,64 \%$ \\
Neurología & 55 & 42 & $76,36 \%$ \\
Órganos de los Sentidos & 33 & 29 & $87,88 \%$ \\
Respiratorio & 18 & 11 & $61,11 \%$ \\
Digestivo & 26 & 17 & $65,39 \%$ \\
Urogenital & 24 & 18 & $75 \%$ \\
Topografia del Abdomen & 10 & 8 & $80 \%$ \\
Endocrino & 5 & 3 & $60 \%$ \\
Topografia & 11 & 10 & $90,91 \%$ \\
\hline
\end{tabular}



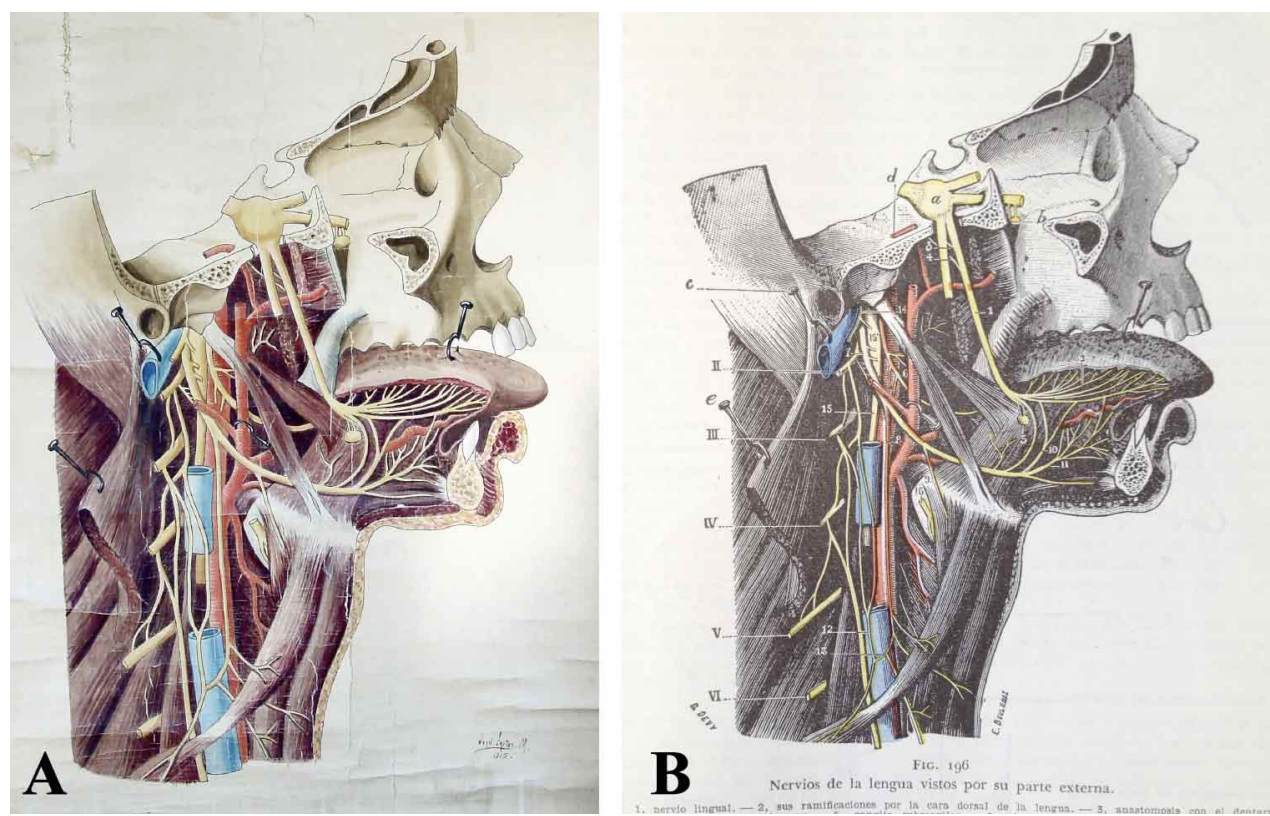

Fig. 7. A. Lámina F21 de la colección, Juan Frutos M. (1915), Técnica mixta sobre tela. B. Grabado de G. Devy en Tratado de Anatomía humana de Leo Testut (1910).

\section{Catalogación}

A partir de los resultados se elaboró un catálogo monográfico (Nagel, 2008) que permitiese visualizar la colección por completo, dedicando una página entera a cada lámina y su ficha correspondiente. Para la organización del catálogo se respetaron el orden original con letras y números, junto con las categorías presentes en los gabinetes que clasificaban las láminas según secciones por temática, siguiendo la tradición histórica de los atlas anatómicos utilizados como referentes (Dinator Esterio). Cada categoría se distingue con un color único representativo.

Se diseñó una ficha de registro para organizar y exponer la información recopilada de las láminas durante la investigación como autoría, fecha de elaboración, dimensiones, iconografía, técnica y materiales. Esta ficha permite visualizar cada lámina en correlación con imágenes y la información de los referentes originales identificados para cada caso, señalando si la lámina corresponde a una copia, es decir, una obra derivada de un referente en un texto de anatomía (Fig. 8).

\section{CONCLUSIONES}

Fueron encargados mayoritariamente en su ejecución por el Profesor Basilio Muñoz Pal, por cuanto en el $100 \%$ de los casos en que se nombra un profesor de Anatomía en los cuadros, es su nombre el que se señala. Esto coincide con la gran producción de láminas posterior al año 1915, fecha en la que Muñoz Pal regresa de Alemania. Sabida es la maestría y afición por el dibujo que el Profesor Muñoz Pal tenía y de lo cual aún sus alumnos recuerdan años más tarde.

Sobre los autores podemos señalar además que no sólo alumnos participaron en la realización de estas láminas, sino también docentes como Solervicens y Luis Vargas S. (1903), este último luego se haría cargo de la cátedra en 1919. Hubo algunos que no se dedicaron a la Medicina sino más bien a las Artes

La fuente de inspiración fueron obras derivadas, libros de anatomía de uso habitual para la época, en la que destaca ampliamente los grabados de Leo Testut en su Tratado de Anatomía, por sobre las inspiraciones personales, llegando a constituir el $71.79 \%$ del total de láminas, de las cuales casi el $85 \%$ eran del autor francés.

Por las consideraciones antes expuestas y como una forma de rendirle un permanente tributo a aquellas generaciones de docentes y alumnos es que se propone la selección de imágenes anatómicas para ser incorporadas al set de imágenes actuales que se utilizan en Docencia, y de esa forma, transmitirle esta información a las nuevas generaciones de alumnos, tanto de Chile como del extranjero. 
CÁRDENAS, V. L. J.; DINATOR, E. M. \& MADARIAGA, L. J. Descripción de las láminas anatómicas de la Universidad de Chile, un monumento nacional Int. J. Morphol., 35(2):711-718, 2017.
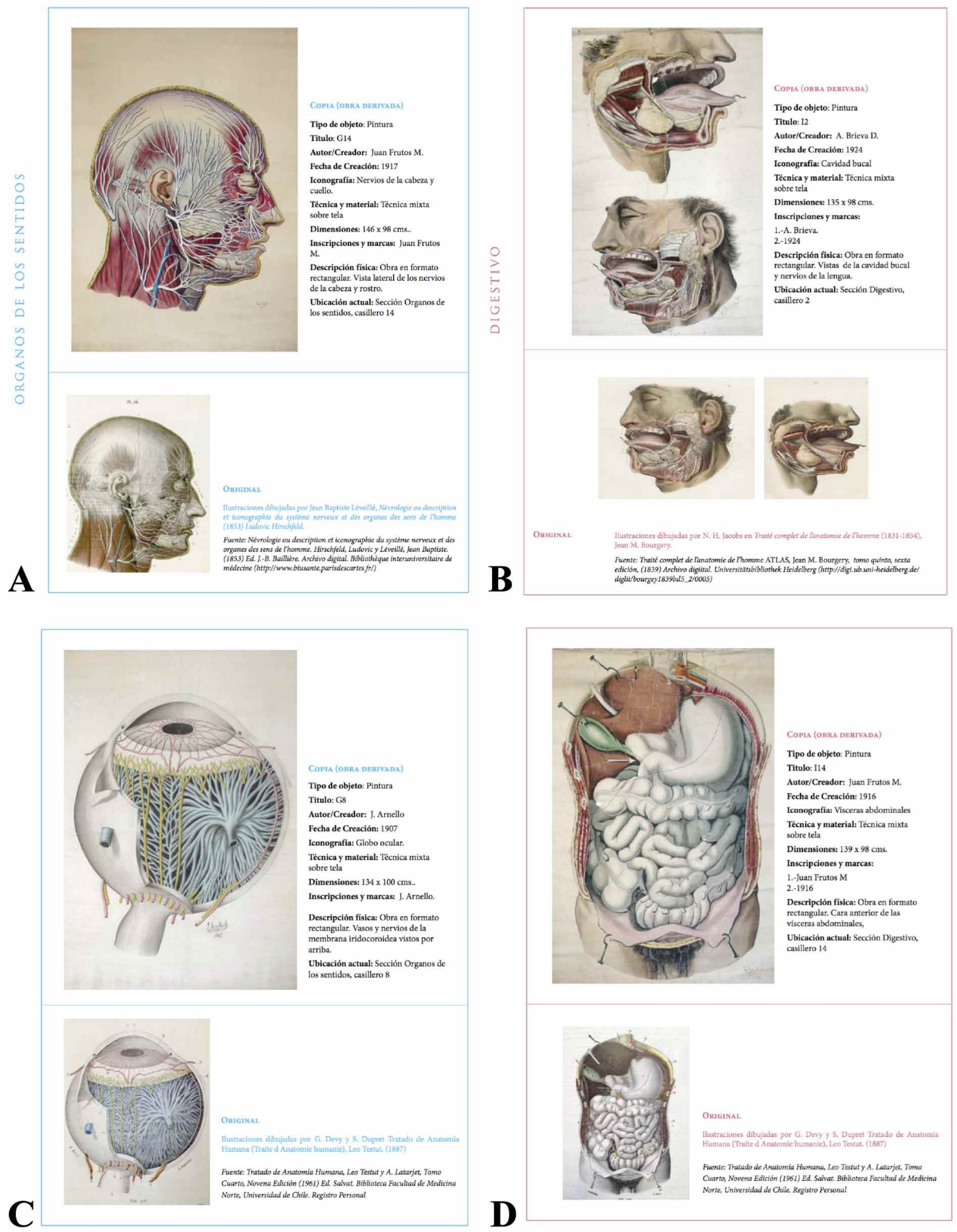

Fig. 8. A. Ficha del catálogo de lámina G14, mostrando el referente original. B. Ficha del catálogo de lámina I2, mostrando el referente original. C. Ficha del catálogo de lámina G8, mostrando el referente original. D. Ficha del catálogo de lámina I14, mostrando el referente original. 
CÁRDENAS, V. L. J.; DINATOR, E. M. \& MADARIAGA, L. J. Description of the anatomical plates of the Universidad de Chile, a, national monument. Int. J. Morphol., 35(2):711-718, 2017.

SUMMARY: In the year 2003, 475 anatomical plates and five lithographs used for teaching anatomy were found underneath the Anatomy Amphitheatre of the Universidad de Chile, where construction began in 1921. Many generations of students, even teachers of Basic Anatomy ignored their existence and the cultural importance of these plates. In an attempt to preserve the plates and lithographs, a digital record was created that year, of all the works in order to afford them their true value and importance, and ensure their future protection. The material was arranged by subject area by students, faculty members and outside individuals, as a mechanism to allow the teaching of anatomy at a time when slides and audiovisual digital material did not exist. They were made using different techniques such as precovered wrapped canvases, stored in specially prepared storage cabinets for their preservation in cold and dark environment, to avoid breakdown and ruin. Therefore, in order to prevent deterioration and allow their conservation, these works were digitalized and a catalogue created for the use of the next generations. This work was further underlined when on January 20, 2016, the State of Chile nominates these anatomical plates a National Monument, in its historical character.

KEY WORDS: Anatomical plates; Teaching anatomy; National monument.

\section{REFERENCIAS BIBLIOGRÁFICAS}

Cárdenas, J. L. El instituto de anatomia de la universidad de Chile. An. Chile. Hist. Med., 16(1):33-42, 2006.

Diario Oficial de la República de Chile. Decreto Número 549, de 2015.Declara Monumento Nacional en la categoría de Monumento Histórico al "Anfiteatro del Instituto de Anatomía" y a las "Colecciones del Museo de Anatomía", todos pertenecientes a la Universidad de Chile, ubicados en la comuna de Independencia, provincia de Santiago, Región Metropolitana. Diario Oficial de la República de Chile, $\mathrm{N}^{\circ} 41.361$, 20 de Enero de 2016.

Dinator Esterio, M. Catálogo de Láminas Anatómicas. Estudio de Visualidad sobre las Ilustraciones Científicas del Cuerpo Humano en la Universidad de Chile (1903-1956). Tesis para optar al título de Diseñador Gráfico. Santiago de Chile, Facultad de Arquitectura y Urbanismo, Universidad de Chile, 2014

Guzmán Cortés, L. Mis recuerdos de estudiante. An. Chile. Hist. Med., 6(1):9-169, 1964

Laval, E. Evolución y desarrollo de la enseñanza de la anatomía en Chile. An. Chile. Hist. Med., 6(2):7-75, 1964.

Nagel, L. (Ed.). Manual de Registro y Documentación de Bienes Culturales. Santiago de Chile, Dibam, 2008.

Zamorano, P. E. Generación de 1913: ¿Heroica capitanía? Atenea (Concepc.), (497):169-74, 2008.
Dirección para correspondencia

Dr. Julio Cárdenas

Médico Cirujano Internista

Prof. Asistente ICBM

Anatomia y Biologia del Desarrollo

Facultad de Medicina

Universidad de Chile

Santiago

CHILE

E-mail: jcardena@med.uchile.cl

Recibido : 10-01-2017

Aceptado : 27-02-2017 